\title{
Kinetics of iso-Propanol Oxidation Catalyzed by TS-1 Membrane Reactor
}

\author{
Pei Chen, Xiangshu Chen, Hidetoshi Kita \\ Department of Advanced Materials Science and Engineering, Faculty of Engineering, \\ Yamaguchi University, Tokiwadai 2-16-1, Ube, Yamaguchi 755-8611, Japan \\ E-mail: Kita@yamaguchi-u.ac.jp
}

Titanium silicalite-1 (TS-1) tubular membrane was used as a catalytic active membrane reactor in the oxidation of iso-propanol with hydrogen peroxide. The TS-1 membrane prepared at $150^{\circ} \mathrm{C}$ showed the highest catalytic activity with the conversions above $90 \%$. The kinetic parameters of the reaction were calculated and a simple column mathematical model was used to describe the catalytic activity of the membrane reactor.

Key words: Zeolite membrane, Titanium silicalite-1, Membrane reactor, Catalysis, Kinetics

\section{INTRODUCTION}

Titanium silicalite-1 (TS-1) zeolite is known to be an efficient catalyst for selective oxidation of organic. It had been employed in industrial processes of phenol hydroxylation [1]. Most of reports to date were emphasized on optimizing the synthesis route and improving the catalytic activity of TS-1 powder. However, two separation processes, catalyst separation from batch solution and product separation from substrates, were necessary in the case of TS-1 powder as catalyst. But if TS-1 membrane is used as membrane reactor, the catalysis reaction will occur in membrane layer when the reactants cross through the membrane layer from feed side to permeate side under the driving force of pressure and concentration gradient, the product will be obtained in the permeate side. Compared with TS-1 powder, the advantage of TS-1 membrane reactor is that the catalysis and separation processes are realized in a unit.

There are few reports on the supported TS-1 membranes. The TS-1/PDMS hybrid membrane prepared by filling TS-1 powders into organic PDMS membrane showed the catalytic activity and separation property [2-4]. TS-1 membrane prepared on a porous support by seeded growth method has no gas separation property [5].

To prepare supported TS-1 membrane by 'in situ' method is a real challenge due to the difficulty in controlling the nucleation and crystallization on porous support. Our group has devoted to the preparation of TS-1 membrane for years. Nowadays, TS-1 membranes with catalytic activity for some oxidation reaction have been successfully prepared by hydrothermal thermal and microwave method [6-8].

The objective of this work was to investigate the catalytic kinetics of TS-1 membrane reactor for the oxidation of iso-propanol (IPA). To achieve this, TS-1 membranes were prepared, and the effects of reaction parameters were studied.

\section{EXPERIMENT}

TS-1 membranes were hydrothermally prepared on $10 \mathrm{~cm}$ long tubular mullite supports (Nikkato, $12 \mathrm{~mm}$ outer diameter, $1.5 \mathrm{~mm}$ thickness and $1.3 \mu \mathrm{m}$ average pore size). Two series of membranes were prepared. The first series were achieved by crystallizing the synthesis gel with molar composition of $\mathrm{SiO}_{2}:(0.01-0.03) \mathrm{TiO}_{2}$ : 0.35TPAOH: $28 \mathrm{H}_{2} \mathrm{O}$ at 150,160 and $170^{\circ} \mathrm{C}$ for certain time. They were coded as $\mathrm{Ml}(\mathrm{T} / \mathrm{t}-\mathrm{X})$. $\mathrm{T}$ represents crystallization temperature, $\mathrm{t}$ crystallization time, and $\mathrm{X}$ the molar ratio of $\mathrm{TiO}_{2} / \mathrm{SiO}_{2}$ in synthesis gel. The second series were obtained by crystallizing the synthesis gel with molar composition of $\mathrm{SiO}_{2}$ : $(0.003-0.02)$ $\mathrm{TiO}_{2}: 0.17 \mathrm{TPAOH}: 120 \mathrm{H}_{2} \mathrm{O}$ at $185^{\circ} \mathrm{C}$ for $48 \mathrm{~h}$. They were coded as $\mathrm{M} 2(\mathrm{~T} / \mathrm{t}-\mathrm{X}), \mathrm{T}, \mathrm{t}$ and $\mathrm{X}$ have the same meaning as above. Tetraethyl orthosilicalite, titanium n-butoxide and Tetrapropylammonium hydroxide $(\mathrm{TPAOH})$ were used as silicon, titanium sources and template, respectively After hydrothermal crystallization, the samples were took out from the autoclave, washed and dried, and then were calcined in air at $500^{\circ} \mathrm{C}$ for $30 \mathrm{~h}$.

$\mathrm{X}$-ray diffraction (XRD) patterns of the powders and membranes were measured by a SHIMADZU XRD-6100 X-ray diffractometer with $\mathrm{CuK} \alpha$ radiation. Fourier infrared (FT-IR) spectra were recorded by a JASCO FT/IR-610 spectrometer. Morphology observation was carried out with scanning electron microscopy (SEM, JEOL 6335F).

For the oxidation of IPA to acetone by TS-1 membrane reactor, the membrane was immersed in the feed solution composed of IPA, $\mathrm{H}_{2} \mathrm{O}_{2}$ and $\mathrm{H}_{2} \mathrm{O}$. Under the pervaporation (PV) condition, the catalysis reaction took place in membrane layer. Samples of feed and permeation were periodically analyzed by a Gas Chromatograph (SHIMADZU GC8A). The flux was calculated by weighing the permeate sample mass. The conversions of IPA was given : $\mathrm{C}_{\mathbb{P A}}=\left(\text { mol }_{\text {acetone }}\right)_{\text {Permeate }}$ $\left(\mathrm{mol}_{\text {acetone }}+\text { mol }_{\text {IPA }}\right)_{\text {Permeate }} \times 100$.

In the case of TS-1 powder, $10 \mathrm{wt} \%$ TS- 1 powder based on the mass of IPA was used. The conversion of IPA was calculated by $C=\left(C_{i}-C_{t}\right) / C_{i} \times 100, C_{i}$ and $C_{t}$ were the concentration of IPA at initial and time $t$, respectively.

\section{RESULTS AND DISCUSSION}

Characterization of TS-1 membranes: All the TS-1 membranes show the typical XRD patterns of titanium silicalite-1 [9]. FT-IR spectra of TS-1 powders collected 
from the bottom of autoclave show a characteristic shoulder peak of TS-1 at about $960-970 \mathrm{~cm}^{-1}$ [9]. These proved that TS-1 membrane was successfully prepared.

Effect of crystallization condition: The conversion of IPA as a function of molar ratio of $\mathrm{TiO}_{2} / \mathrm{SiO}_{2}$ in synthesis gel is presented in Fig.1. The crystallization temperature and the molar ratio of $\mathrm{TiO}_{2} / \mathrm{SiO}_{2}$ have great influence on membrane catalytic activity. Lower crystallization temperature benefits to the catalytic activity. For M1 and M2 series membranes, the conversion of IPA monotonically increases with increasing molar ratio of $\mathrm{TiO}_{2} / \mathrm{SiO}_{2}$ in synthesis gel. Thus, the highest conversion of $94 \%$ was obtained in the case of M1(150/72-0.03) membrane.

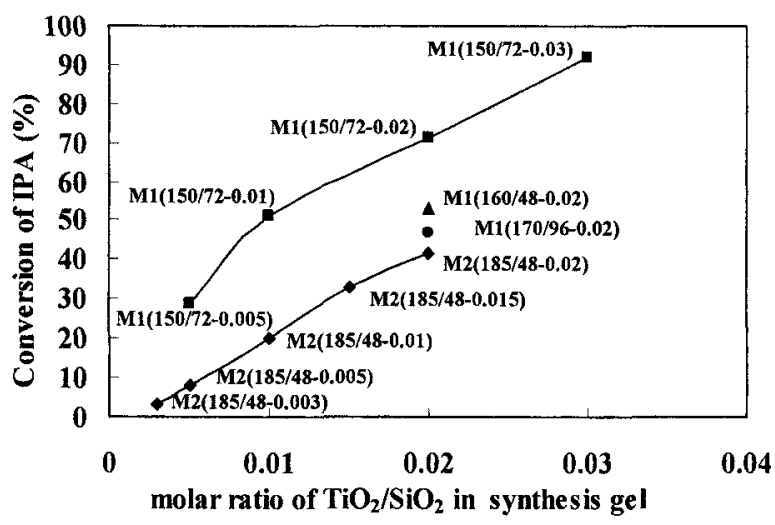

Fig.1 IPA conversion as a function of $\mathrm{TiO}_{2} / \mathrm{SiO}_{2}$ molar ratio in initial synthesis gel for $\mathrm{M} 1$ and $\mathrm{M} 2$ series membranes

Effect of reaction temperature: IPA conversion increased with increasing reaction temperature. M1(150/72-0.03) membrane exhibited higher activity than M2(185/48-0.02). The 100\% IPA conversion was achieved at $55^{\circ} \mathrm{C}$ for $7 \mathrm{~h}$ by TS- 1 powder, and conversion of $94 \%$ was obtained for M1(150/72-0.03) membrane at $60^{\circ} \mathrm{C}$ for $8 \mathrm{~h}$. The conversion of IPA was less than $60 \%$ at $60^{\circ} \mathrm{C}$ after $13 \mathrm{~h}$ for $\mathrm{M} 2(185 / 48-0.02)$ membrane .

Effect of IPA/ $\mathrm{H}_{2} \mathrm{O}_{2}$ ratio: The effect of $I P A / \mathrm{H}_{2} \mathrm{O}_{2}$ ratio was studied at $50^{\circ} \mathrm{C}$ with $10 \mathrm{wt} \%$ of IPA concentration in reaction solution (Fig.2). When the molar ratio of $\mathrm{IPA} / \mathrm{H}_{2} \mathrm{O}_{2}=2: 1, \mathrm{H}_{2} \mathrm{O}_{2}$ was completely consumed after $2 \mathrm{~h}$ in the case of TS-1 powder, and the conversion of IPA was about $33 \%$. In the case of $\mathrm{M} 1(150 / 72-0.03)$ membrane, the needed time was only $0.5 \mathrm{~h}$. At IPA $/ \mathrm{H}_{2} \mathrm{O}_{2}=1: 1$, the conversion of IPA was about $70 \%$ after $2 \mathrm{~h}$ in TS- 1 powder system, while $90 \%$ after $0.5 \mathrm{~h}$ and $94 \%$ after $1.5 \mathrm{~h}$ in the case of $\mathrm{Ml}(150 / 72-0.03)$ membrane. At IPA $/ \mathrm{H}_{2} \mathrm{O}_{2}=1: 2$, IPA conversion rate was further increased, and up to $100 \%$ after $1.8 \mathrm{~h}$ for TS-1 powder system. However, for Ml(150/72-0.03) membrane, the reaction rate and conversion of IPA had nearly no change similar to the case of $1 \mathrm{PA} / \mathrm{H}_{2} \mathrm{O}_{2}=1$. This indicated that the catalyst state as powder or membrane have different influence on the catalysis process.
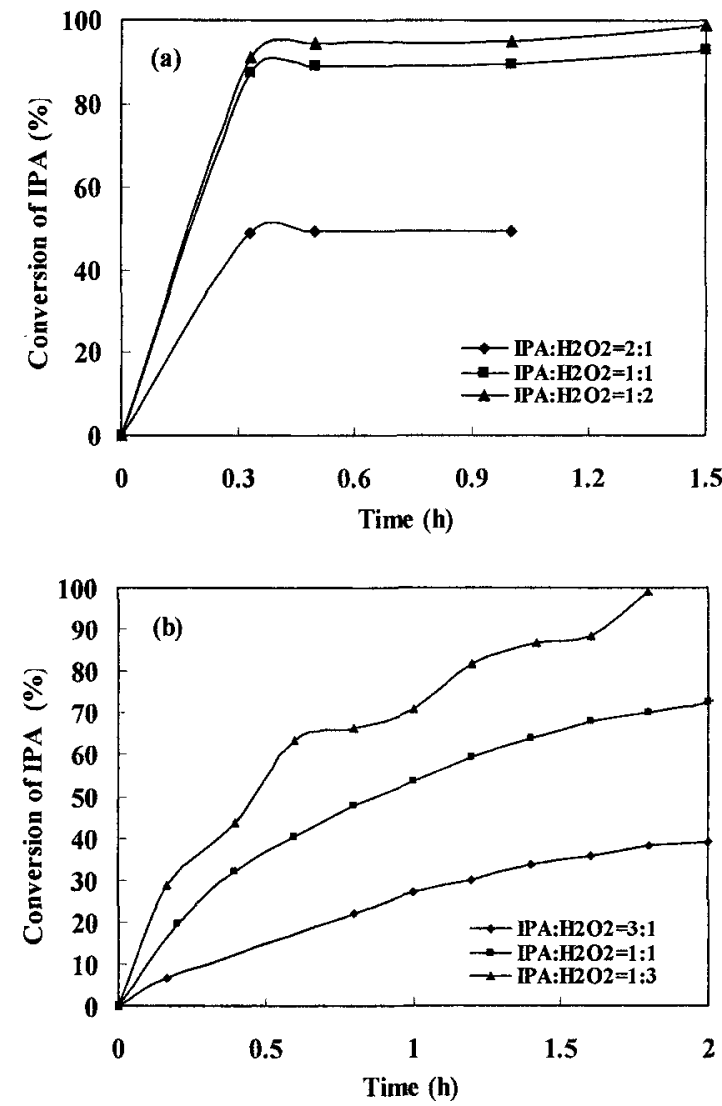

Fig. 2 plots of IPA conversion versus reaction time for different molar ratio of $1 \mathrm{PA} / \mathrm{H}_{2} \mathrm{O}_{2}$ with (a) M1(150/72-0.03) membrane and (b) TS-1 powder

Apparent Kinetic parameters: The isolated method was used to obtain reaction order of IPA and $\mathrm{H}_{2} \mathrm{O}_{2}$ at $50^{\circ} \mathrm{C}$ in the case of TS-1 powder as catalyst. The obtained apparent reaction rate equation was

$$
r=k\left(\mathrm{C}_{I P A}^{\mathrm{t}}\right)^{0.84}\left(\mathrm{C}_{H 2 O 2}^{\mathrm{t}}\right)^{0.15}
$$

The apparent reaction activation energy and apparent reaction rate constant in the rang of $40-55^{\circ} \mathrm{C}$ were obtained from the fitted equation by Arrehenius method, they were $E_{\text {app }}=86.1 \mathrm{KJ} / \mathrm{mol}, k_{o}=5.33 \times 10^{13}$ and the correlation factor $\left(R^{2}\right)$ was 0.995 . In the case of M1(150/72-0.03) membrane, $E_{\mathrm{app}}=84.65 \mathrm{KJ} / \mathrm{mol}, k_{o}=$ $8.82 \times 10^{13}$ and $R^{2}=0.953$ in the range of $20-60^{\circ} \mathrm{C}$. The linearity of fitted line was bad in the case of M2(185/48-0.02) membrane.

Column catalysis model: It has been known that the diffusion limitation of reactants in TS-1 pore channel decided the catalytic activity of TS-1 powder [10]. When TS-1 membrane was used under PV condition, the adsorption and desorption resistances of reactant in TS-1 channel will seriously influence its diffusion rate, and thus indirectly decide the catalytic activity. Combining all of these factors, the mathematic formulation of the reaction rate of IPA was established with the column model (Fig. 3) because the reaction occurs in the column channels of TS-1 framework structure. 


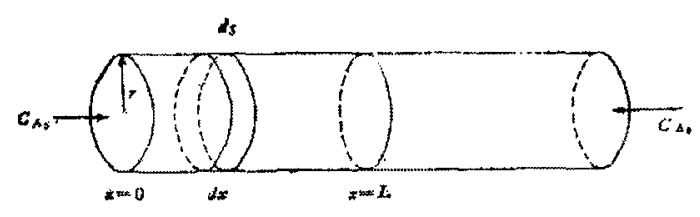

Fig. 3 illustration of column model

According $2^{\text {th }}$ Fick law and the mass balance, mass transfer differential equation in $d x$ volume can be described as:

$$
\begin{gathered}
-\pi r^{2} D\left(\frac{d C_{A}}{d x}\right)_{x}+\pi r^{2} D\left(\frac{d C_{A}}{d x}\right)_{x+d x}=\pi r^{2} D \frac{d^{2} C_{A}}{d x^{2}} d x \\
\pi r^{2} D \frac{d^{2} C_{A}}{d x^{2}} d x=2 \pi r d x k C_{A}
\end{gathered}
$$

Boundary conditions are:

$$
\begin{aligned}
& x=0, \quad C_{A}=C_{A o} ; \\
& x=L, \quad d C_{A} / d x=0 .
\end{aligned}
$$

The calculated reaction rate in channel with $L$ dimension is:

$$
\omega_{L}=\pi r^{2} D C_{A 0} \frac{h}{L} \tanh (h)
$$

for n-order reaction, the reaction rate in unit volume catalyst is:

$$
\omega=\frac{18}{d_{p}{ }^{2}} \rho_{B} V_{g} D C_{A o} h_{n} \tanh \left(h_{n}\right)
$$

where

$$
h_{n}=L \sqrt{\frac{2 k_{n} C_{A 0}^{(n-1)}}{r D}}
$$

$d_{p}$ zeolite crystal particle size, $\rho_{B}$, stack density of TS- 1 crystals in or on mullite support, $V_{g}$, specific micropore volume of TS-1 crystal which is close to that of silicalite-1 $\left(0.19 \mathrm{~cm}^{3} / \mathrm{g}\right), D$, diffusion coefficient of reactant molecule in TS-1 channel; $C_{A 0}$, initial concentration of reactant outside of zeolite pore; $k_{n}$, reaction rate constant; $n$, the intrinsic reaction order, $r$, radius of zeolite pore $(0.55 / 2(\mathrm{~nm}))$.

M1(150/72-0.03) membrane: SEM images clearly showed that the crystals $(\approx 1 \mu \mathrm{m})$ stacked loosely on or in support [6,7]. Furthermore this membrane has no separation ability for IPA/H $\mathrm{H}_{2} \mathrm{O}$ and acetone $/ \mathrm{H}_{2} \mathrm{O}$ systems under $\mathrm{PV}$ condition, which indicated that the mass transport was carried out by defects. In this case, the most possible factor deactivating the catalytic site is that the small amount of IPA molecule stacked on the pore opening, and thus inhibiting the reactant molecules to further enter the channel, which results in the catalyst deactivation. Here, the length of deactivation zone in zeolite channel was assumed as $\alpha L$ in Fig. 4.

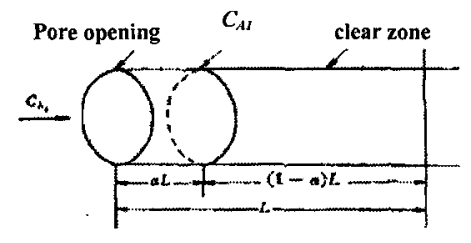

Fig. 4 illustration of deactivation in M1(150/72-0.03) membrane
The reaction rate in channel after and before deactivation are:

$$
\begin{aligned}
& \omega_{\text {deact }}=\frac{\left\{\pi r \sqrt{2 r k D} \tanh \left[h_{o}(1-\alpha)\right]\right\} C_{A o}}{1+\alpha h_{o} \tanh \left[h_{o}(1-\alpha)\right]} \\
& \omega_{\text {bef }}=C_{A o} \pi r \sqrt{2 \pi r k D} \tanh \left(h_{o}\right)
\end{aligned}
$$

the catalytic efficiency is:

$$
F=\frac{\omega_{\text {deacet }}}{\omega_{o}}=\frac{1}{1+\alpha h_{o} \tanh \left[h_{o}(1-\alpha)\right]} \cdot \frac{\tanh \left[h_{o}(1-\alpha)\right]}{\tanh \left(h_{o}\right)}
$$

in n-order reaction,

$$
h_{o}=h_{n}=L \sqrt{\frac{2 k_{n} C_{A 0}^{(n-1)}}{r D}}
$$

In experiment, $C_{I P A}^{o}=C_{H 2 O 2}^{o} \approx 1.65 \mathrm{~mol} / \mathrm{L}$, and apparent reaction order obtained form TS-1 powder was near to 1 . $D$ belongs to the molecular with the lowest diffusion rate in the reaction solution. $\mathrm{H}_{2} \mathrm{O}_{2}$ has the similar chemophysical property to $\mathrm{H}_{2} \mathrm{O}$, which has much higher diffusion rate in silicalite-1 channel than that of IPA [11]. Here, the diffusion coefficient of IPA of $10^{-13} \mathrm{~m}^{2} / \mathrm{s}$ [11] was as $D$. The value of $r$ was about $1 \mu \mathrm{m}$ from SEM, so the length of zeolite channel $L$ was assumed $0.5 \mu \mathrm{m}$ in $b$-axis of crystals. The value of apparent $k$ obtained from the plots of $\log r \sim \log C_{I P A}^{t}$ in $20-50^{\circ} \mathrm{C}$ was in the range of 0.1-7, which can be used as $K_{n}$ in equation (9). So the the estimated value of $h_{o}=h_{n} \approx 10^{5} \geqslant 2$, and $\tanh \left(h_{o}\right) \approx 1$. In this condition, equation (8) can be changed to the follows:

$$
F=\frac{1}{1+\alpha h_{o}}
$$

It can be deduced that only in the case of $\alpha \approx 0$, the highest catalysis efficiency would be achieved. That means that the number of IPA molecular stacking on the pore opening was low. That is, TS- 1 membrane did not preferably adsorb the organic compound from water, and the concentration of organic in permeate side was near to that in feed side. PV separation experiments in the system of IPA/ $\mathrm{H}_{2} \mathrm{O}$ and acetone $/ \mathrm{H}_{2} \mathrm{O}$ just proved this, in which the concentration of organic in the permeated side was very close to that in the feed. So, this membrane exhibited high catalytic activity.

Quantitative comparison of the catalytic efficiency: It should be noted that the values of some parameters in equation (5), which was use to describe the reaction rate, were different for M1(150/72-0.03) and M2(185/48-0.02) membranes. For both membranes, the intrinsic catalysis reaction was same, $k_{n}$ and $n$ were not changed; $C_{A 0}$ was constant in experiments. $V_{g}$ and $r$ were the constants of TS- 1 crystal. $D$ at the same experiment condition was constant. So, the reaction rate equation (5) can be changed as:

$$
\omega \propto \frac{1}{d_{p}{ }^{2}} \rho_{B} D h_{n} \tanh \left(h_{n}\right)
$$

Because $h_{n} » 2$ and $\tanh \left(h_{n}\right) \approx 1$, equation (11) was simplified as equation (12)

$$
\omega \propto \frac{\rho_{B} L}{d_{p}^{2}}
$$


For M1(150/72-0.03) membrane, the stack density $\rho_{B}$ was not even from SEM observation. It was assumed that all the crystals were distributed in the column shell with $0.01 \mathrm{~cm}$ thickness. The mass of TS- 1 loaded on the support was about $0.45 \mathrm{~g}$, which was obtained by weighing the mass of the calcined membrane and the support, respectively. So

$$
\rho_{B}(M 1)=\frac{m}{V}=\frac{m}{\pi\left(r_{\text {out }}^{2}-r_{\text {int }}^{2}\right) l}
$$

where $l$ was the effective length of membrane, it usually was $0.63 \mathrm{~cm} . r_{o u t}=1.2 \mathrm{~cm}$ and $r_{i m}=1.19 \mathrm{~cm}$ was support parameters. So, $\rho_{B}(M I) \approx 0.951 \mathrm{~g} / \mathrm{cm}^{3}$.

For M2(185/48-0.02) membrane, the polycrystallinity dense layer was presumed as a single crystal, and $\rho_{B}$ (M2) should be equal to the intrinsic density of crystal. Because the content of $\mathrm{Ti}$ in framework was much less than that of $\mathrm{Si}$, the intrinsic density of TS-1 can be substituted with that of silicalite-1. It is known of $1.8 \mathrm{~g} / \mathrm{cm}^{3}$.

$L$ represented that the effective length of zeolite channel. For M1(150/72-0.03) membrane, because the crystal size was about only lum, it was reasonable to presume $L(M I)=0.5 \mathrm{um}$. For M2(185/48-0.02) membrane, just as the case of $\rho_{B}$, the polycrystallinity layer was considered as a single crystal. The effective length of zeolite channel that reactant molecule must pass through from feed side to permeate side was assumed as: $l=\delta A . \delta$ was tortuous factor for the two-dimension channel in MFI structure, and $A$ was the thickness of polycrystallinity layer on support outer-surface. For solid catalyst $\delta$ was usually 2-4, $A$ obtained by direct measurement was about 10-15um. When $\delta=2, A=10 \mu \mathrm{m}$, $L(M 2)=20 \mu m$.

According SEM, the particle size of TS- 1 crystal $d_{p}(M 1)=1 \mu m$ for $\mathrm{Ml}(150 / 72-0.03)$ membrane, and $d_{p}(M 2)=15 \mu \mathrm{m}$ for $\mathrm{M} 2(185 / 48-0.02)$ membranc.

$$
\text { So } \quad M=\frac{\omega(M 1)}{\omega(2)}=2.97
$$

Equation (14) showed that the molar or mass of obtained of acetone in permeated side in unite time for M1(150/72-0.03) membrane was 2.97 times higher than M2(185/48-0.02) membrane. This was proved by experiment. In Table I, the flux of product acetone for M1(150/72-0.03) membrane was about 2.5-3.5 times of M2(185/48-0.02) membrane. So the established reaction rate equation (5) based on column model can explain the experiment results.

Table I. the catalysis performance of TS- 1 membrane under PV condition*

\begin{tabular}{llll}
\hline Membrane & $\begin{array}{l}\text { Total } \\
\text { flux }\left(\mathrm{kg} / \mathrm{m}^{2} \mathrm{~h}\right)\end{array}$ & $\begin{array}{l}\text { Acetone } \\
\text { flux }\left(\mathrm{kg} / \mathrm{m}^{2} \mathrm{~h}\right)\end{array}$ & $\begin{array}{l}\text { Conversion } \\
\text { of IPA(\%) }\end{array}$ \\
\hline M2-1 & 0.64 & 0.046 & 67 \\
M2-2 & 0.61 & 0.036 & 64 \\
M1-1 & 1.13 & 0.117 & 94 \\
M1-2 & 1.17 & 0.117 & 92 \\
M1-3 & 1.36 & 0.128 & 91 \\
\hline
\end{tabular}

*Catalysis condition: $10 \mathrm{wt} \%$ IPA solution, molar ratio of IPA $/ \mathrm{H}_{2} \mathrm{O}_{2}=1, T_{\text {reacion }}=50^{\circ} \mathrm{C}$.

\section{CONCLUSION}

Supported TS-1 membrane was prepared by 'in situ' hydrothermal treatment method. Oxidation of iso-propanol was selected as probe reaction to test the catalytic activity of the obtained membranes. TS-1 membrane prepared at $150{ }^{\circ} \mathrm{C}$ showed the highest catalytic activity with the conversions above $90 \%$, while TS-1 membrane prepared at $185^{\circ} \mathrm{C}$ had relatively low catalyyic activity. A column mathematical model was used to describe the discrepancy of catalytic activity between these two series membranes.

\section{References:}

[1] B.Kraushaar, J.H.C.Van Hoof, Catal. Lett., 1, 81-84 (1988).

[2]. S. Wu, C. Bouchard, S.Kaliaguine, Res. Chem. Interm., 24, 273-290 (1998).

[3] S. Wu, J.Gallot, M.Bousmina, C.Bouchard, S. Kaliaguine, Cata.Today, 56,113-129 (2000).

[4] I.Vankelecom, K.Vercruysse, N.Moens, R.Parton, J.S.Reddt, P.Jacobs, J.Chem. Soc.Chem. Comm., 137-138 (1997).

[5] L. Tak, Y. Au, J. Lik, H.Chau, C. T. Ariso, K. L. Yeung, J.Membr.Sci.,183, 269-291 (2001).

[6] X. Chen , Ph.D. Thesis, Yamaguchi University, Japan, (2005).

[7] X. Zhang, X. Chen, H. kita, K. Okamoto, Trans. Mater. Res. Soc., 30, 393-396 (2005).

[8] H. Kita, K. Okamoto, X. Chen, M. Kondo, J. Abe, Jpn, Pat. No.3840507.

[9] A.Thangaraj, R.Kumar, S.P.Mirajkar, J.Catal. 130, 1-8 (1991).

[10] A. J. H. P. van der Pol, A.J.Verduyn, J.H.C.Van Hooff, Appl.Catal.A: General, 92,113-130 (1992).

[11] T. C. Bowen, J.C.Wyss, R.D.Noble, J.L.Falconer, Micro. Meso. Mater., 71, 199-210 (2004).

(Received January 20, 2007;Accepted May 10, 2007) 